\title{
ENTREVISTA COM MYRA BERGMAN RAMOS
}

\author{
Kamilla Corrêa Loivos ${ }^{1}$ \\ 1 Universidade do Estado do Rio de Janeiro, Rio de Janeiro, Rio de Janeiro,
}

Brasil

Paulo Freire (1921-1997) foi um importante e conhecido educador e até hoje sua obra é utilizada e referenciada em universidades, congressos e pesquisas. A Pedagogia do Oprimido foi escrita durante seu exílio no Chile (1967-1968) e possui uma trajetória editorial peculiar, pois foi traduzida para o inglês, publicada nos Estados Unidos, em 1970, vertida para outros idiomas e publicada em outros países. Apenas em 1974, foi publicada no Brasil em português pela Editora Paz e Terra.

Pedagogy of the Oppressed foi traduzida por Myra Bergman Ramos, nascida em 1936, em Spokane/Washington. Myra Bergman Ramos não era, e não se tornou, uma tradutora profissional. No entanto, após a versão de Pedagogia do Oprimido para o inglês, traduziu, também para o inglês, Educação Como Prática da Liberdade (Education: The Practice of Freedom) e o prefácio de Extensão ou Comunicação? (Extension or communication), ambos de Paulo Freire. Essas duas versões foram publicadas juntas como Education for Critical Consciousness, pela Continuum Publishing Company em 1973. Myra não realizou outros trabalhos como tradutora. Como Pedagogy of the Oppressed completa cinquenta anos de publicação em 2020, apresenta-se abaixo a compilação de três entrevistas realizadas com Myra Bergman Ramos, em 2019. 
Cadernos de Tradução (CT): Por que veio ao Brasil e como foi o aprendizado de português?

Myra Bergman Ramos (MR): Eu tinha ido, no ano prévio, para a União Soviética e eu estava fazendo Estudos Russos. Fiz parte de um grupo de intercâmbio estudantil e estive fazendo uma palestra, mais ou menos, sobre minha viagem para um grupo do ACM estudantil e Richard Shaull esteve como parte do grupo. Estávamos fazendo almoço e a pessoa ao meu lado se levantou, foi-se embora para outro canto e o Shaull sentou-se ao meu lado. Começamos a conversar. Parece que ele gostou do que eu tinha falado. Eu já tinha lido o livro dele e gostava do livro dele. Ele falou sobre o Brasil e eu sabia o nome de Luiz Carlos Prestes, ele ficou impressionado que eu soubesse. E, então, ele me perguntou o que eu ia fazer depois de ganhar o meu mestrado e eu disse que eu não sabia, que talvez eu fosse à Tailândia. E ele disse: "Não, você não quer a Tailândia, não, não. Você quer o Brasil". E eu disse: "Mas ninguém me convidou". E um pouco depois recebi o convite para servir a um "projeto piloto" para um programa da Igreja Presbiteriana dos EUA chamado Frontier Internship in Mission (FIM), o que precedeu e se parecia um pouco com o Corpo de Paz.

Foi por acaso, sabe? Muita coisa foi por acaso nesse projeto. Trabalhei, com salário mínimo, para a associação cristã acadêmica, um grupo ecumênico de universitários protestantes.

Passei umas duas semanas em Campinas estudando português na escola para missionários da Igreja Presbiteriana. Depois de me mudar para o Rio de Janeiro, passei a estudar com uma professora particular. Penso, é difícil de me lembrar exatamente, que no princípio passava uma hora por dia com ela; depois algumas vezes por semana. Depois de três meses pude conversar razoavelmente. 
(CT): Por quanto tempo morou no Brasil?

(MR): Morei no Rio de Janeiro, desde agosto de 1959 até novembro/ dezembro de 1960. Voltei para os Estados Unidos em 1960 para me casar com Jovelino Ramos. Depois voltamos para o Rio em 1962, em julho ou agosto, e ficamos até junho de 1968. A família voltou para os Estados Unidos por causa do golpe militar. Pretendíamos voltar, mas o estado militar durou bastante, como sabe.

(CT): Conheceu o nome de Paulo Freire quando estava no Brasil?

$(M R)$ : Claro. Era um nome famoso, mas não o conheci pessoalmente. Não houve qualquer ocasião e eu não estava envolvida na política naquela primeira época, sabe? Estávamos lidando com estudantes e a nossa missão era de fazer um trabalho ecumênico, de um protestantismo mais ecumênico, mais liberal, foi o nosso foco na época. Foi depois de voltar, em 1962, que tudo tinha mudado durante aquele ano e meio. Todos os estudantes que conhecíamos antes estavam sendo radicalizados, a política estava na frente de tudo. $\mathrm{Na}$ minha primeira visita eu estava estudando português para poder lidar com os estudantes. E eu já tinha estudado o espanhol um pouquinho no secundário, eu tinha estudado o russo bastante por ter ido à União Soviética. Mas eu gostei do português, tive uma certa facilidade e acabei retendo até agora.

(CT): Sobre o trabalho de tradução da Pedagogia do Oprimido, quando foi feito e em que local morava à época?

$(M R)$ : Havia voltado para os Estados Unidos. E eu estava tentando me lembrar de quando exatamente recebi o convite e eu não consigo lembrar. Eu vejo que a publicação do livro que eu tenho aqui ao meu lado foi em 1972 (Myra está se referindo ao livro da edição

Cad. Trad., Florianópolis, v. 40, n 2, p. 365-376, mai-ago, 2020. 
de 1972, publicado pela Herder and Herder New York). Em 1972, a editora foi Herder and Herder. E pode ver que o Prefácio é do Richard Shaull.

Devo enfatizar que fui tradutora novata, sem treinamento profissional. Minha indicação foi informal, na base do amigo mútuo Richard Shaull. Entendo que requereu bastante trabalho editorial. Não tive na época muita ideia da importância da tradução que fiz. Poderia dizer que fui tradutora acidental de uma obra seminal.

(CT): Esta edição que tem em mãos é a única que traz, na folha de rosto, a informação de que o livro foi traduzido direto do manuscrito.

$(M R)$ : E nem sei agora onde está o manuscrito que recebi para fazer a tradução. Deve estar entre os meus papéis quem sabe onde, mas não encontrei. Porque fiz anotações, perguntas para fazer a Paulo. Tudo o que você quer saber, mas eu não sei onde está.

(CT): Foi muito importante encontrá-la. Aqui no Brasil não há informações sobre a senhora. Nos livros em inglês, tenho cinco edições em mãos, há a informação de que foi a senhora quem traduziu. Uma das grandes interrogações dessa obra é que muitos idiomas fizeram a tradução do inglês e não a tradução do manuscrito em português.

(MR): É verdade.

(CT): Não há registro disso para estudo. Então, precisamos pesquisar para entender, inclusive, qual é o livro lido no Brasil. Eu tenho este livro em português: edição 60 de 2016. Sabemos que há uma parte do manuscrito que não está no livro em português. A obra mais completa é a sua. 
(MR): Eu estava pensando antes dessa conversa, tentando lembrar uns pontinhos importantes. E uma das coisas que o Paulo me disse, que eu tive de rir, foi que, de vez em quando, ele olhava para o manuscrito em português e dizia: "Hum, o que eu queria dizer com isso?". Então ele ia olhar o livro em inglês e dizia: “Ah, ah, era isso!”.

(CT): Ele escreveu um livro chamado Pedagogia da Esperança no qual fala sobre a Pedagogia do Oprimido e fala um pouco sobre o seu trabalho como tradutora. Ele cita o seu nome várias vezes e diz que você participou muito, que vocês conversavam muito durante a tradução. Sobre esse processo seria importante saber o que se recorda, comofoi feito, em que contexto. Encontrava-se pessoalmente com ele ou só o conheceu depois que começou a traduzir?

$(M R)$ : Foi depois, e quase que não me encontrei com ele pessoalmente naquela época. Depois, sim. Mas a gente se escrevia, nos telefonávamos e eu o consultava sobre uma palavra, uma frase... Nós discutíamos a tradução, mas eu não lembro dos detalhes.

Eu não sabia que ia ser uma obra de tanta duração. Mas eu sabia que ele era um homem de grande importância e que eu ia fazer um trabalho que honrava a seriedade do pensamento dele. E desconfio que eu não tenha sido a pessoa perfeita para ser escolhida, sabe? Eu nunca tinha feito nada parecido. E uma coisa com a tradução que eu aprendi é: uma parte tentar ser fiel ao pensamento, às palavras do livro na primeira língua; mas o outro problema é ter palavras em inglês que parecem ser em inglês.

E eu trabalhei e eu tentei muito isso. Não sei, não tenho certeza que eu tenha sido muito feliz com isso. Fiz o melhor. Minha mãe, dizia: "Ah, mas acho que isso fica melhor assim em inglês".

Eu estava casada, com três filhos pequenos. Estava trabalhando em tempo integral, em Nova York. No fim do dia, a gente fazia jantar, arrumava, lia para as crianças, colocava-as na cama, e então estava na hora de eu começar a fazer trabalho de tradução. E muitas vezes eu acabava dormindo porque estava exausta. E estava custando o 
progresso. Meu marido estava ficando nervoso, mas eu não sabia fazer mais rápido. Então aconteceu uma coisa inconveniente para a minha saúde, mas conveniente para a tradução. É que eu tive uma coagulação de sangue na perna e tive que ficar de cama durante umas semanas. Pronto! Terminei! Foi um pequeno milagre, que entrou e salvou o projeto.

Parte do contexto, do período em que estava fazendo a tradução, foi o movimento feminista dos Estados Unidos. Estava começando, tomando forma. Fiquei influenciada e há um ponto, enquanto eu estava traduzindo, em que me dei conta de que toda a linguagem do manuscrito original é masculina, tudo. Ele, ele, ele, ele. Então, eu falei com o Paulo e perguntei: "Oi, Paulo. Você já pensou que os conceitos descritos no seu livro se aplicam às relações entre os homens e as mulheres?". E ele disse: "Não, nada disso. Não tem nada a ver com gênero, tem tudo a ver com classe". E eu disse: “Tá bom, tá bom". Bom, a edição que saiu um pouco depois corrigia seu léxico para ser mais inclusivo entre homens e mulheres. E, anos depois, eu conversei novamente com Paulo. Eu recontei a conversa que tive com ele, a pergunta que eu fiz e a resposta dele. Ele me olhou e disse: "Estive errado". Ele já havia se tornado mais aberto neste assunto de feminismo e machismo.

(CT): Sobre essas escolhas que vocês precisaram fazer de termos e palavras, eu, observando os livros em inglês, vi que há uma palavra que se manteve em português até o final: "conscientização".

(MR): Na época, a frase consciousness raising, que foi muito proeminente no movimento feminista, não tinha entrado na língua. Então eu estava tentando pensar e não conseguia imaginar uma frase certa. Então o que eu fiz foi definir, na página 19, a primeira página do prefácio. Eu defino e, então, retenho. 
(CT): O que eu observei, em português, quando a gente vai traduzir, há o termo awareness, que é "consciência”. Em alguns momentos há quem ache que pode também se referir à conscientização. Eu achei curioso e pensei: "provavelmente é porque não quer dizer essa conscientização que o Paulo traz para o livro”. Até porque em outros momentos a senhora usa critical awareness, self awareness, mas quando o termo é "conscientização" não foi feita a tradução, foi mantido.

$(M R)$ : Sabe, eu estava olhando o que eu coloquei como definição e, para Paulo, acho que conscientização é mais do que awareness. É uma awareness que leva a gente à ação. A ação é parte do significado da palavra.

(CT): Até hoje nos livros se mantém em português, isso é muito interessante. Porque quando a senhora falou para mim agora que naquele momento o termo do movimento feminista não havia sido aceito e por isso a escolha de explicar e manter em português, hoje, cinquenta anos depois, eu tenho o livro que foi lançado no ano de 2018 em edição comemorativa aos 50 anos do manuscrito $e$ "conscientização" continua em português. Então não é só isso também. Acabou se tornando um termo chave, um termo intraduzivel, porque a sua tradução não foi mexida. Até erros de digitação se mantiveram, uma palavrinha que passou na hora da revisão da editora. É o mesmo texto, isso é muito curioso. Como pode um texto ser o mesmo até hoje e as editoras imprimirem ano após ano o mesmo texto sem alterar nada. A senhora falou que foi "uma tradutora acidental de uma obra seminal". E é isso mesmo! É muito importante, foi muito importante.

Qual foi o impacto profissional na sua vida após a tradução da obra Pedagogia do Oprimido?

$(M R)$ : É um dos feitos de que tenho mais orgulho. Até hoje encontro pessoas cujas vidas foram transformadas pelo livro. Entendo 
que Cesar Chavez foi muito influenciado por Pedagogia do Oprimido, o que é uma grande honra. O impacto tem sido mais pessoal do que profissional, uma vez que passei a fazer uma carreira de Administração Acadêmica.

Vem gente falar comigo até hoje ao saber que eu fui a tradutora, e dizem: "Ah, mas foi o livro que mais mudou a minha vida!". Mas duas coisas que eu lembrei sobre isso também. A linguagem, em português, como pode ver, porque que tem acesso aí, é bastante difícil. Não é um português fácil, não. E Paulo, na época, estava muito influenciado pelos filósofos alemães. Então os conceitos foram bastante difíceis. Algumas pessoas aqui nos Estados Unidos reclamaram que a tradução era difícil, não era fácil. Se Paulo era realmente o professor dos oprimidos, que não sabiam ler, como a linguagem deste livro era tão difícil? E eu só podia dizer: "Devia ter visto no manuscrito original, era muito mais difícil!". A outra coisa é que não tive muito contato com a editora Herder and Herder. Quando estava tudo pronto para publicar, o editor me falou: “É um livro bonzinho, mas nunca será um best-seller!". Ele estava enganado, mas quem sabia? Eu não sabia.

(CT): Quanto tempo levou para traduzir o livro inteiro?

(MR): Deve ter sido quase um ano, eu acho.

(CT): Ao longo dessa tradução, fazia contato só com Paulo Freire $e$ as pessoas que ajudavam nos termos? Havia algum contato com as editoras?

$(M R):$ Ah, só no início, quando eu entrei. A tradução foi anotada por algumas pessoas que melhoraram o inglês, o flow, mas foram realmente Paulo e meu marido os mais ativos com o português e, então, minha mãe pelo inglês propriamente dito. 
(CT): Houve alguma censura ao seu texto?

$(M R)$ : Não, não. Fizeram, em alguns pontos do texto, o inglês sair mais inglês. Mas não censuraram nada, não mudaram o significado de nada.

(CT): No Brasil, a edição em português sofreu censura. A senhora se lembra de um gráfico em forma de desenho que estava no livro $e$ vocês traduziram (a teoria da ação revolucionária e da ação opressora)? Em inglês, ele está na página 131 dessa edição que possui. Em português, até hoje não foi publicado. Uma questão muito interessante é saber que a Pedagogia do Oprimido só pôde ser publicada no Brasil porque foi muito bem recebida em vários países, e também nos Estados Unidos, a partir da tradução do inglês. A data da primeira publicação em inglês é 1970, mas eu realmente só consigo a edição de 1972.

$(M R)$ : É isso que eu tenho. E este é o livro em que Paulo me escreveu. Aqui ele diz: “À Myra, não apenas a tradutora excelente, a quem este livro também pertence, mas a amiga fraterna. Um abraço de Paulo Freire. Nova York, janeiro de 1973".

(CT): Após essa tradução, não teve mais vontade ou oportunidade de trabalhar como tradutora, não quis escolher essa profissão, por quê?

$(M R)$ : Bom, é interessante a pergunta. Meu então marido, meu primeiro marido, por exemplo, traduziu inúmeros livros para o inglês. Ele gostou do trabalho e começou a fazer. Eu não, sabe? Eu dei tudo que tinha, tentando fazer essa tradução. Devo dizer que meu então marido, Jovelino Ramos, colaborou comigo na tradução, embora tenha recusado a citação do seu nome como tradutor oficial.

Logo depois, me divorciei do meu marido. Tive três filhos pequenos, precisava nos sustentar, não foi fácil. Fui mãe solteira durante 
muitos anos, antes de me casar de novo. E foi realmente difícil. Não recebi grande pagamento pela tradução e foi um pagamento fixo. E eu acho interessante que só talvez há três anos recebi notícia do grupo The Authors Registry, em Nova York, que queriam me mandar direitos autorais da Grã-Bretanha. Parece que muitos cursos universitários requerem o livro ou capítulos e há um grande trabalho de cópia. Então, eles me mandam. Não é grande coisa, mas eu recebo duas ou três vezes por ano.

(CT): De acordo com algumas pesquisas, verifiquei que traduziu outros livros de Paulo Freire. Saberia me dizer quais?

(MR): Traduzi Educação Como Prática da Liberdade; também o prefácio de Extensão ou Comunicação?. (O ensaio Extensão ou Comunicação? mesmo foi traduzido por Louise Bigwood e Margaret Marshall.) Os dois estudos foram publicados juntos como Education for Critical Consciousness, pela Continuum Publishing Company em 1973.

(CT): Continuou trabalhando como secretária acadêmica?

$(M R):$ Eu comecei há muitos e muitos anos quando eu era uma mãe solteira tentando sobreviver como secretária. Mas tive a sorte de subir dentro da estrutura acadêmica até ter uma posição de bastante responsabilidade, um bom salário e tudo isso. Eu fui Associate Dean for Educational Services, me aposentei em 1998 da Harvard Medical School e voltei ao meu estado natal.

(CT): Alguma outra recordação sobre a questão do aprendizado da língua portuguesa, da escolha do seu nome para traduzir a Pedagogia do Oprimido e do contexto que vivia no período? 
$(M R)$ : Estou pensando agora sobre a minha aprendizagem da língua que não foi acadêmica. Tive esse estudo mais ou menos particular, sabe? Eu andava pelas ruas fazendo meu trabalho e no fim do dia ia visitar a minha professora particular, com todas as frases, todas as palavras que não tinha entendido. Então íamos indo. Tudo foi na base da experiência pessoal. E a outra coisa foi minha vida com estudantes, que estavam muito influenciados, não somente por Paulo, mas por todos os grupos políticos por aí. Foi um ambiente tremendamente político.

Foi um pouco antes de 1962 até 1968. E houve o primeiro golpe, em 1964, não é? E em 1968 a gente via que as coisas estavam piorando. Era muito provável que haveria um segundo golpe, o que aconteceu em dezembro. Meu então marido tinha visto de saída somente até março. Ele tinha que sair, não iam renovar. Então, ele saiu em março, eu saí em junho, com os três filhos. Foi a pior viagem que já fiz na minha vida.

Tudo estava enormemente político. Pode ter sido por isso que o Shaull me convidou. Porque a gente estava lidando com os estudantes, conversando sobre tudo isso. Eu não conhecia o Paulo pessoalmente. Eu devia ter perguntado a Shaull porque ele me selecionou. Nunca pensei em perguntar. Mas para mim foi boa sorte, não é?

\section{Referências}

Chesterman, Andrew. "O nome e a natureza dos Estudos do Tradutor.". Traduzido por Patrícia Rodrigues Costa e Rodrigo D’Avila Braga Silva. Belas Infiéis. 3.2 (2014): p. 33-42. Disponível em: http://periodicos.unb.br/index.php/belasinfieis/ article/view/11280/9925. Acesso em: 04 de março de 2019. 
Feire, Paulo (a). Pedagogy of the Oppressed. Traduzido por Myra Bergman Ramos. New York: Herder and Herder, 1972.

Freire, Paulo (b). Pedagogia do Oprimido. $60^{\mathrm{a}}$ ed. Rio de Janeiro: Paz e Terra, 2016.

Recebido em: 07/12/2019

Aceito em: 24/03/2020

Publicado em maio de 2020

Kamilla Corrêa Loivos. E-mail: kk.loivos@gmail.com ORCID: https://orcid. org/0000-0002-8143-1958 